\title{
Weekly versus Daily Iron Supplementation for Preventing Iron deficiency Anaemia Amongst Children Between Six to 24 Months: A Randomised Control Trial
}

\section{Sneha Kaushik, Anita Yadav, Pradeep Kumar Debata and Kailash Chandra Aggarwal}

Department of Paediatrics, Vardhman Mahavir Medical College and Safdarjung Hospital, Delhi, India

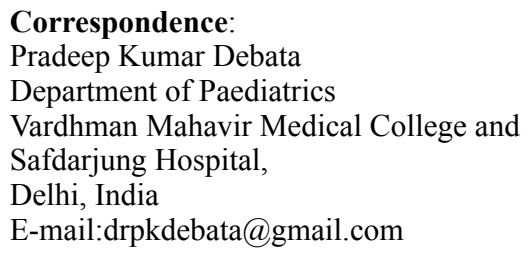

E-mail:drpkdebata@gmail.com

DOI: $10.3126 /$ jnps.v39i3.28272

Submitted on: 2020-03-29

Accepted on: 2020-05-05

\section{Acknowledgements: None}

Funding: Nil

Conflict of Interest: None declared

Permission from IRB: Yes
To cite this article: Kaushik S, Yadav A, Debata PK, Aggarwal KC. Weekly versus daily iron supplementation for preventing iron deficiency anaemia amongst children between six to 24 months: A randomised control trial. J Nepal Paediatr Soc. 2019;39(3):174-80.

\section{ABSTRACT}

Introduction: Iron deficiency anaemia is common in developing nations and starting iron supplementation from infancy is an important measure for its prevention. There is still not enough evidence, whether giving iron twice weekly as compared to daily, is enough to prevent the same.

Methods: This open-labeled randomised control trial was conducted at a tertiary care facility over a period of 1.5 years. After informed consent from parents, a total of 125 non-anaemic healthy infants in age group six to 24 months; with birth weight $>$ 2500 grams, born singleton at term gestation and predominantly breastfed in the first six months of life; were randomised using computer generated sequence to two groups. Control group received daily elemental iron supplementation of $1 \mathrm{mg} / \mathrm{kg} / \mathrm{day}$ and the intervention group received twice weekly $2 \mathrm{mg} / \mathrm{kg} /$ day. Haemoglobin, serum ferritin were measured at enrolment and at the end of 100 days. Primary outcome was anaemia defined as haemoglobin less than $11 \mathrm{mg} / \mathrm{dl}$. Secondary outcome measures were weight gain, increase in length and occipito-frontal circumference.

Results: Baseline characteristics were similar in the two groups. This study showed significantly higher mean haemoglobin $(\mathrm{mg} / \mathrm{dl})$ (mean \pm SD $11.882 \pm 0.3237,11.683 \pm 0.4264, \mathrm{p}=0.009)$ and mean serum ferritin $(\mathrm{ng} / \mathrm{ml})$ (mean $\pm \mathrm{SD} 101.704 \pm 23.0263$, $62.149 \pm 24.2079, \mathrm{p}=0.000$ ) at end of 100 days in the control group than the intervention group. There was no difference in any of the secondary outcomes.

Conclusions: Biweekly iron supplementation can also prevent iron deficiency anaemia in children between six to 24 months of age but daily is better in respect to the increase in haemoglobin.

Key words: anaemia; anaemia prevention; iron deficiency; iron supplementation; serum ferritin

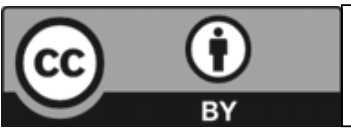

This work is licensed under creative common attribution 3.0 license 


\section{INTRODUCTION}

Iron deficiency anaemia (IDA) is the most prevalent nutritional deficiency worldwide which affects growth and development. ${ }^{1}$ The global prevalence of anaemia among the pre-school children is $47.4 \% .^{2}$ Haemoglobin concentration of the newborn infant falls during the first two to three months of life, considerable iron is reclaimed and stored are sufficient for blood formation in the first six to nine months of life in term infants. ${ }^{3}$ Iron deficiency usually starts manifesting around the age of six months. By four months of age, neonatal iron stores get reduced by half and exogenous iron is required to meet the needs of normal growth and development. The American Academy of Paediatrics (AAP) recommends that daily iron supplementation should be initiated at the age of four months in term infants. ${ }^{4}$ The World Health Organisation (WHO) has recommended that intermittent iron supplementation is an effective alternative to daily iron supplementation in preschool age group. ${ }^{5}$

Daily iron supplementation beginning in late infancy in predominantly breast fed term infants has been documented to increase haemoglobin by $0.7 \mathrm{~g} / \mathrm{dl}$ after two months of iron supplementation. ${ }^{6}$ However, daily iron supplementation results in higher incidence of gastrointestinal side effects leading to poor compliance. ${ }^{7}$

During infancy, daily iron supplementation is recommended ${ }^{4}$, but some clinical trials have shown that intermittent iron supplementation (e.g., biweekly, every third day) is as efficacious as daily supplementation in terms of improving iron status. ${ }^{8-10}$ Decreasing frequency to biweekly may increase the compliance due to lesser side effects; is cost effective and may increase the efficiency of iron supplementation during infancy. However, daily administration was more efficacious (by about $5-10 \%$ ) than the weekly regimen in most scenarios considered. ${ }^{11-13}$ The focus of action which was formerly placed on treatment has now moved on to the prevention of IDA. To date, the efficacy of biweekly iron supplementation has not been investigated fully in healthy, term, exclusively breast-fed infants. In addition, studies on routine iron supplementation among exclusively breast-fed infants are also limited. So, the purpose of this study is to determine the efficacy of daily and weekly iron supplementation for 100 days to improve the iron status of six to 24 months old healthy babies without anaemia.

\section{METHODS}

This open labeled randomised study was carried out over a period of 1.5 years at a tertiary care teaching hospital in the outpatient department of Paediatrics. The trial was registered with central trials registry of India CTRI: REF/2018/02/017594. The institutional ethics committee approved the study. Subject were healthy infants in the age group six to 24 months with birth weight $>2500$ grams, born singleton at term gestation and predominantly breastfed in the first six months of life. Those with anaemia defined as haemoglobin less than $11 \mathrm{gm} /$ $\mathrm{dl}$, congenital malformation, already on iron supplements and those who received blood transfusion were excluded. Other parameters like demographic, maternal factors were also recorded. Subjects were randomised using computer generated sequence to two groups and 1:1 allocation ratio after taking informed consent from the parents or guardians. Sample size was calculated as 50 in each group with power $90 \%$ to detect $30 \%$ difference in haemoglobin between the two groups, $5 \%$ significance, $10 \%$ attrition rate on follow up at three months. A total of 125 children were recruited. 61 children were randomised to control group to receive daily elemental iron (liquid preparation containing $100 \mathrm{mg}$ elemental ferrous sulphate plus folic acid $0.5 \mathrm{mg}$ per $5 \mathrm{ml}$ available from hospital supply) supplementation at $1 \mathrm{mg} / \mathrm{kg} /$ day and 68 to intervention group to receive weekly at $2 \mathrm{mg} / \mathrm{kg} /$ day.

Primary outcome was anaemia defined as haemoglobin less than $11 \mathrm{gm} / \mathrm{dl}$. Secondary outcome measures were weight, length and occipito-frontal circumference (OFC). Haemoglobin, serum ferritin, peripheral smear for type of anaemia and anthropometry were taken at baseline and after three months of iron supplementation. Babies were followed monthly for three months. 
Haemoglobin was analysed using cyanide free method automated analyser (Sysmex XT-2000i and KX-21 which uses fluorescent flow cytometry principle using the direct current detection method with coincidence correction). Serum ferritin was measured by using immune-radiometric assay (Beckman Coulter Access-2). Weight was measured using lever scale to the nearest $100 \mathrm{~g}$. OFC was measured using a non-stretchable measuring tape with least count of one $\mathrm{mm}$. The length was measured with the help of infantometer to the nearest one $\mathrm{mm}$. Data was analysed using SPSS for Windows (SPSS Inc.,Chicago, IL). P value less than 0.05 was taken as significant.

\section{RESULTS}

A total of 125 babies fulfilled the recruitment criteria \& were enrolled for the prospective follow up. At the end of three months, 51 babies in control group and 53 in intervention group could be followed up. (Figure 1).

Baseline characteristics were similar in the two groups. (Table 1) Daily supplementation group had significantly higher mean haemoglobin $(\mathrm{gm} / \mathrm{dl})$ (mean \pm SD 11.882 $\pm 0.3237,11.683 \pm 0.4264, p=$ $0.009)$ and mean serum ferritin (ng/ml) (mean \pm SD $101.704 \pm 23.0263,62.149 \pm 24.2079, \mathrm{p}<0.001)$ as compared to biweekly group after three months of supplementation.

The means of the percentage increase in haemoglobin and serum ferritin showed similar results $(\mathrm{p}<0.05)$ when compared in different subgroups male:female and six to 12 and 12 to 24 months age group babies. Both daily and weekly groups had normocytic normochromic picture on the peripheral blood smear after 100 days of supplementation. No significant difference was observed in any of the secondary outcome variables weight, length and head circumference after three months of supplementation in both the groups (Table 2).

\section{DISCUSSION}

The objective of the study was to evaluate the efficacy of daily versus weekly iron supplementation in non-anaemic children in the age group of six to 24 months. Both the groups were

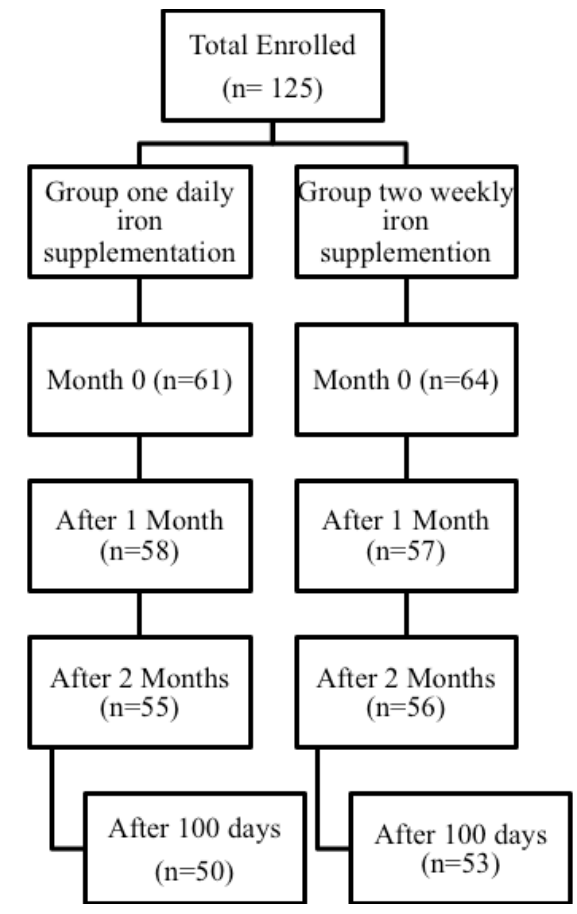

Figure 1. Study Flow Chart

comparable considering the basal characteristics, which indicates good randomisation. The possible reasons for the loss of follow up (17.6\%) could be reporting from a distance and loss of wages, lack of perceived benefit of medication in apparently healthy children, prolonged duration of medication for no apparent disease and poor educational and socioeconomic status.

The age group of six to 24 months was selected as high prevalence of iron deficiency anaemia is seen in this age group due to the progressive depletion of iron stores, inadequate dietary intake of iron and the low bioavailability of iron in the complementary feeds introduced after six months of age. ${ }^{14-17}$

This study showed that after 100 days of iron supplementation, the daily group had a significantly higher haemoglobin, haemoglobin increase in percentage and serum ferritin as compared to the weekly group. The increase in serum ferritin was not found by some researchers in healthy nonanaemic breast fed infants. ${ }^{21}$

Various studies have compared daily with biweekly iron supplementation. Azeredo et al. studied 103 non-anaemic children aged between six to 18 
Table 1. Baseline data

\begin{tabular}{|c|c|c|c|}
\hline Maternal Parameters & Daily Iron Group $(n=50)$ & Weekly Iron Group $(n=53)$ & p Value \\
\hline Age (yrs)* & $24.16 \pm 3.171$ & $23.64 \pm 2.639$ & 0.368 \\
\hline Weight (kg)* & $59.94 \pm 6.57$ & $57.94 \pm 6.488$ & 0.124 \\
\hline Height (cms) * & $158.69 \pm 3.446$ & $158.16 \pm 2.979$ & 0.405 \\
\hline Parity* & $1.82 \pm 0.720$ & $1.77 \pm 0.869$ & 0.769 \\
\hline Place of Delivery- Hospital & $45 \pm 90$ & $47 \pm 88.7$ & 0.828 \\
\hline Gestational age (weeks) & $38.34 \pm 1.287$ & $38.75 \pm 1.518$ & 0.139 \\
\hline $\begin{array}{l}\text { Mode of Delivery } \\
\text { Vaginal\# } \\
\text { Caesarean\# }\end{array}$ & $\begin{array}{l}36(72) \\
14(28)\end{array}$ & $\begin{array}{l}34(64.2) \\
19(35.8)\end{array}$ & 0.394 \\
\hline $\begin{array}{l}\text { Iron supplementation } \\
\text { Number (No.) \# } \\
\text { Dose (mg/day) } \\
\text { Duration (months) }\end{array}$ & $\begin{array}{l}18(36) \\
60 \\
3\end{array}$ & $\begin{array}{l}23(43.4) \\
60 \\
3\end{array}$ & $\begin{array}{r}0.873 \\
- \\
-\end{array}$ \\
\hline Children Parameters & & & \\
\hline Age (months)* & $14.26 \pm 7.001$ & $13.11 \pm 5.679$ & 0.184 \\
\hline Sex: Male (\%) \# & $29(58)$ & $35(66)$ & 0.401 \\
\hline Birth weight (kg) & $2.808 \pm 0.2237$ & $2.742 \pm 0.1769$ & 0.101 \\
\hline Birth length (cms) & $49.97 \pm 0.626$ & $49.64 \pm 0.651$ & 0.010 \\
\hline OFC at birth (cms) & $34.16 \pm 0.348$ & $34.35 \pm 0.362$ & 0.08 \\
\hline Weight at recruitment (kg) & $9.210 \pm 1.5488$ & $9.132 \pm 1.4779$ & 0.794 \\
\hline Length at recruitment (cms) & $75.52 \pm 7.6944$ & $74.142 \pm 6.3248$ & 0.322 \\
\hline OFC at recruitment (cms) & $44.82 \pm 1.7779$ & $44.792 \pm 1.5110$ & 0.933 \\
\hline Hemoglobin (g/dl) & $11.49 \pm 0.796$ & $11.42 \pm 0.454$ & 0.576 \\
\hline Serum Ferritin (ng/ml) & $56.404 \pm 34.4221$ & $52.649 \pm 26.1854$ & 0.533 \\
\hline $\begin{array}{l}\text { Peripheral smear } \\
\text { Normocytic-normochromic\# } \\
\text { Normocytic hypochromic\# } \\
\text { Microcytic hypochromic\# }\end{array}$ & $\begin{array}{l}28(56) \\
9(18) \\
13(26)\end{array}$ & $\begin{array}{l}42(79.2) \\
9(17) \\
2(3.8)\end{array}$ & 0.005 \\
\hline
\end{tabular}

${ }^{*}$ Mean $\pm S D$, \# number (percentage)

months and Engstrom et al six to 12 months and showed daily supplementation was more efficacious without difference in side effects and adherence in both the groups. ${ }^{18,19}$ They used only haemoglobin concentration as the outcome variable and serum ferritin levels were not measured. A study in Kenya by Desai et al. concluded that daily iron supplementation was better than biweekly iron supplementation. ${ }^{20}$ However, the study population was between two months to five years, mild to moderately anaemic and the region was endemic for malaria.

All the above-mentioned studies have corroborated the findings of our study; that daily iron supplementation is superior to intermittent iron supplementation. Few studies, in the similar age groups by Arcanjo et al. and Hademloo et al. have concluded that both weekly and daily iron supplementation were effective in increasing haemoglobin levels and reducing anaemia in infants but an increase in serum ferritin levels was seen only with daily iron supplementation. ${ }^{10,11}$

Some studies have compared the efficacy of biweekly and daily supplementation in anaemic children in different age groups like in Indonesia by Schultink et al..$^{22}$ and Thu et al. ${ }^{9}$ (had cases similar to our age group) and found similar results but better adherence in biweekly group. Tavil et al. 
Table 2. Primary and Secondary outcomes

\begin{tabular}{|lrrrrrrr|}
$\begin{array}{l}\text { Values at 3 } \\
\text { months of iron }\end{array}$ & $\begin{array}{l}\text { Daily iron } \\
\text { group }(\mathbf{n}=\mathbf{5 0}) *\end{array}$ & $\begin{array}{l}\text { Weekly iron } \\
\text { group }(\mathbf{n}=\mathbf{5 3})^{*}\end{array}$ & $\mathbf{p}$ Value & \multicolumn{2}{l}{$\begin{array}{l}\text { \% change in daily } \\
\text { iron group }\end{array}$} & $\begin{array}{l}\text { \% change in } \\
\text { weekly iron group }\end{array}$ & p Value \\
\hline $\mathrm{Hb}(\mathrm{g} / \mathrm{dl})$ & $11.88 \pm 0.32$ & $11.68 \pm 0.42$ & 0.009 & $3.66 \pm 4.12$ & $2.33 \pm 1.75$ & $<0.001$ \\
$\begin{array}{l}\text { Serum ferritin } \\
(\mathrm{ng} / \mathrm{ml})\end{array}$ & $101.70 \pm 23.02$ & $62.14 \pm 24.20$ & $<0.001$ & $172.85 \pm 222.12$ & $26.51 \pm 26.9$ & $<0.001$ \\
Weight $(\mathrm{Kg})$ & $10.19 \pm 1.19$ & $10.10 \pm 1.21$ & 0.862 & $11.61 \pm 6.45$ & $11.43 \pm 5.68$ & 0.625 \\
Length $(\mathrm{cm})$ & $78.61 \pm 6.7745$ & $77.34 \pm 5.51$ & 0.298 & $4.26 \pm 1.91$ & $4.44 \pm 1.55$ & 0.460 \\
OFC $(\mathrm{cm})$ & $45.56 \pm 1.25$ & $45.57 \pm 1.11$ & 0.979 & $1.73 \pm 1.43$ & $1.77 \pm 1.27$ & 0.207 \\
\hline
\end{tabular}

${ }^{*}$ Mean $\pm S D, p<0.05$ is significant

found biweekly regime to be superior with higher haemoglobin and serum ferritin levels, lesser side effects and being cost effective, as compared to daily regime in 94 anaemic Turkish children in the age group of five months to six years. ${ }^{23}$ All these studies showed equal benefits in both types of supplementation in anaemic children and not the normal healthy children. Systematic review in Cochrane database by De-Regil et al. concluded that intermittent iron supplementation was as effective as daily iron supplement in improving haemoglobin (MD $-0.60 \mathrm{~g} / \mathrm{L}, 95 \% \mathrm{CI}-1.54$ to 0.35 , 19 studies) and ferritin concentrations (MD -4.19 $\mu \mathrm{g} / \mathrm{L}, 95 \%$ CI -9.42 to $1.05,10$ studies) and advocated intermittent iron supplementation for public health interventions in settings where daily supplementation has failed or has not been implemented. ${ }^{24}$

In the latest meta-analysis by Tom E et al. in 2020, subgroup analyses by frequency of supplementation showed a significant difference in risk of anaemia among daily versus weekly iron-folic acid regimens, with weekly regimens showing greater benefit ( $\mathrm{p}$ for subgroup differences $=0.01$ ), though only one study contributed data to the latter group. ${ }^{25}$ We did not find any difference in anthropometric measurements between the two study groups after three months of supplementation and these findings were similar to Smuts et al. ${ }^{26,27}$

Pasrichia et al. conducted systematic review and meta-analysis, included included 45 studies with 42000 children aged four to 23 months of age with daily iron supplementation and found children randomised to iron had slightly lesser length (SMD $-0.83,-1.53$ to -0.12 ; eight studies, $\mathrm{n}=868$ ) and weight gain $(-1.12,-1.19$ to -0.33$)$. They felt the need of adequately powered studies to address the uncertain adverse effect profile and effect on growth with daily iron supplements. ${ }^{28}$

Though meta-analyses and systematic review by Low $\mathrm{M}$ et al amongst school age children found daily iron supplementation to improve age-adjusted height among all children and age-adjusted weight among anaemic children; adherence was good but safety concerns remained. ${ }^{29}$ We studied healthy breast fed children and found increase in both serum ferritin and haemoglobin by iron supplementation which is also a clear recommendation stated by review of systematic reviews for iron supplementation. ${ }^{30}$ Considering increase in both the haemoglobin and serum ferritin, which is a marker of iron storage, it is prudent to supplement iron daily to prevent anaemia in cases of increased requirement or loss from the body as in poor nutrition and warm infestation, both of which are very common in developing countries.

There are some limitations to the study. Firstly, the compliance to treatment in both groups could only be assessed telephonically and relied on the parents verbal statements at the time of assessment points. Secondly, we did not study the cognitive outcomes or the side effect profile of iron supplementation in both groups, which is a concern raised by few studies.

\section{CONCLUSIONS}

Biweekly iron supplementation can also prevent iron deficiency anaemia in healthy non-anaemic children between six to 24 months of age, but daily supplementation is better with respect to increase in haemoglobin. 


\section{REFERENCES}

1. Lozoff B, Jiang Y, Li X, Zhou M, Richards B, Xu G, et al. Low-Dose Iron Supplementation in Infancy Modestly Increases Infant Iron Status at 9 Mo without Decreasing Growth or Increasing Illness in a Randomised Clinical Trial in Rural China. J. Nutr. 2016; 146:612-21. DOI: 10.3945/jn.115.223917.

2. Benoist B, McLean E, Egli I, Cogswell M, editors. Worldwide prevalence of anaemia 1993-2005: WHO global database on anaemia. Geneva, Switzerland: World Health Organisation; 2008. [cited 4 December 2015]

3. Norma B, Sills L, Sells R. In: Kliegman RM, Behrman RE, Stanton BF, St. Geme J, Schor N, editors. Nelson textbook of pediatrics. 19th ed. Philadelphia: Saunders. 2010:1655-8.

4. Baker RD, Greer FR. Clinical Report_-Diagnosis and Prevention of Iron Deficiency and Iron-Deficiency Anaemia in Infants and Young Children (0 - 3 Years of Age). Paediatrics. 2010;126(5):1040-50. DOI:10.1542/peds. 2010-2576.

5. WHO. Guideline: Intermittent iron supplementation in preschool and school-age children. Geneva; World Health Organisation 2011.

6. Nagpal J, Sachdev HP, Singh T, Mallika V. A randomised placebo-controlled trial of iron supplementation in breastfed young infants initiated on complementary feeding: effect on haematological status. J Health Popul Nutr. 2004;22(2):203-11. PMID: 15473523.

7. Sharma B, Mahajan H. A comparative study of alternate iron and folic acid supplementation regimes in childhood anaemia. Nat J Med Res. 2014;4(1): 33-6.

8. Thu BD, Schultink W, Dillon D, Gross R, Leswara ND, Khoi HH. Effect of daily and weekly micronutrient supplementation on micronutrient deficiencies and growth in young Vietnamese children. Am J Clin Nutr. 1999;69:80-6. DOI: 10.1093/ajen/69.1.80.

9. Arcanjo F, Santos P, Arcanjo C, Magalhaes S, Leite I. Daily and weekly iron supplementations are effective in increasing hemoglobin and reducing anemia in infants. Journal Trop Pediatr. 2013;59(3):175-9. DOI: 10.1093/ tropej/fms071.

10. Khadelmoo M, Karami H, Ajami A, Yasari M. Comparison of effectiveness of weekly and daily iron supplementation in 6 to 24 months old babies in urban health centres of Sari, Iran. Pak J Bio Sci. 2009;12(2):195-7. DOI: $10.3923 /$ pjbs.2009.195.197

11. Gross R, Benade S, Lopez G. International research on infant supplementation: RandomiSed control trials of micronutrient supplementation during infancy. J Nutr. 2005;135:628S-30S.

12. Hop L.T., Berger J. Multiple micronutrient supplementation improves anaemia, micronutrient nutrient status, and growth of Vietnamese infants: Double-blind, randomised, placebo-controlled trial. J. Nutr. 2005; 135:660-665. DOI: $10.1093 / \mathrm{jn} / 135.3 .660 \mathrm{~S}$

13. De-Romana GL, Cusirramos S, de Romana DL, Gross R. Efficacy of multiple micronutrient supplementation for improving anemia, micronutrient status, growth, and morbidity of Peruvian infants. J. Nutr. 2005;135:646-52. DOI: $10.1093 / \mathrm{jn} / 135.3 .646 \mathrm{~S}$

14. Dallman PR, Tsang R, Nichols B. Nutrition during Infancy. Philadelphia: Hanley and Belfus Inc. 1988;216-95.

15. Kotecha PV. Nutritional anemia in young children with focus on Asia and India. Indian J Community Med. 2011; 36(1):8-16. DOI: 10.4103/0970-0218.80786

16. Zimmermann M, Hurrell R. Nutritional iron deficiency. Lancet. 2007;370:511-20. DOI: 10.1016/ S0140-6736(07)61235-5

17. De-Regil LM, Suchdev PS, Vist GE, Walleser S, Pena-Rosas JP. Home fortification of foods with multiple micronutrient powders for health and nutrition in children under two years of age. Cochrane Database Syst. Rev. 2011;7:CD008959. DOI: 10.1002/14651858.CD008959.pub2.

18. Azeredo CM, Cotta RMM, Santana LFR, Franceschini SCC, Ribeiro RCL, Lamounier JA, et al. Greater effectiveness of daily iron supplementation scheme in infants. Rev Saude Publica. 2010;44(2):1-9. DOI: 10.1590/ s0034-89102010000200002 
19. Engstrom EM, de Castroll IRR, PortelaI M, Cardoso LO, Monteiro CA. Effectiveness of daily and weekly iron supplementation in the prevention of anaemia in infants. Rev Saude Publica. 2008;42(5):1-9. DOI: https://doi.org/ $10.1590 / \mathrm{S} 0034-89102008005000043$

20. Desai M, Dhar R, Rosen D, Kariuki S, Shi YP, Kager P, et al. Daily iron supplementation is more efficacious than twice weekly iron supplementation for the treatment of childhood anaemia in western Kenya. J.Nutr. 2004;134: 1167-74. DOI: https://doi.org/10.1093/jn/134.5.1167

21. Cai C, Granger, Eck PM, Friel J. Effect of daily iron supplementation in healthy exclusively breastfed infants: A systematic review with meta-analysis. Breastfeed Med. 2000;12(10):597-603. DOI: 10.1089/bfm.2017.0003

22. Schultink W, Gross R, Gliwitzki M, Karyadi D, Matulessi P. Efficacy of daily versus twice weekly iron supplementation in Indonesian preschool children with low iron status. Am J Clin Nutr. 1995; 61:111-5.

23. Tavil B, Sipahi T. Effect of twice weekly versus daily iron treatment in Turkish children with iron deficiency anemia. Pediatr Hematol Oncol. 2003;20:319-26. DOI: 10.1080/08880010390203107

24. De-Regil LM, Jefferds MED, Sylvetsky AC, Dowswell T. Intermittent iron supplementation for improving nutrition and development in children under 12 years of age. Cochrane Database of Syst Rev. 2011:12. DOI: 10.1002/14651858.CD009085.pub2.

25. Tam E, Keats EC, Rind F, Das JK, Bhutta AZA. Micronutrient Supplementation and Fortification Interventions on Health and Development Outcomes among Children Under-Five in Low- and Middle-Income Countries: A Systematic Review and Meta-Analysis. Nutrients. 2020;12(2):289. DOI: 10.3390/nu12020289.

26. Smuts C, Dhansay M, Faber M, van Stuijvenberg M, Swanevelder S, Gross R, et al. Efficacy of multiple micronutrient supplementation for improving anaemia, micronutrient status, and growth in South African infants. J.Nutr. 2005;135(3):653-9. DOI: 10.1093/jn/135.3.653S

27. Gera, T, Sachdev HS, Boy E. Effect of iron-fortified foods on haematological and biological outcomes: Systematic review of randomised controlled trials. Am J Cli Nutr. 2012;96:309-24. DOI: 10.3945/ajcn.111.031500

28. Pasricha SR, Hayes E, Kalumba K, Biggs BA. Effect of daily iron supplementation on health in children aged 4-23 months: A systematic review and meta-analysis of randomised controlled trials. Lancet Glob Health. 2013;1:77-86. DOI: $10.1016 / \mathrm{S} 2214-109 \mathrm{X}(13) 70046-9$

29. Low M, Farrell A, Biggs BA, Pasricha SR. Effects of daily iron supplementation in primary-school-aged children: systematic review and meta-analysis of randomised controlled trials. CMAJ. 2013;185(17):791-802. DOI: 10.1503/ cmaj. 130628.

30. Ponce CM, Polman K, Roos N, Wieringa FT, Berger J, Doak CM. What Approaches are Most Effective at Addressing Micronutrient Deficiency in Children 0-5 Years? A Review of Systematic Reviews. Matern Child Health J. 2019;23(1):4-17. DOI: 10.1007/s10995-018-2527-9. 